\title{
Experimental and numerical analysis of blast response of High Strength Fiber Reinforced Concrete slabs
}

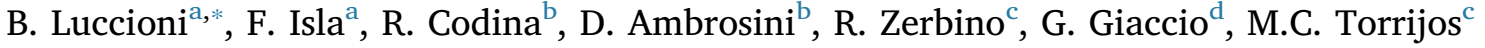 \\ a CONICET, Structures Institute, National University of Tucumán, Av. Independencia 1800, 4000 S.M. de Tucumán, Argentina \\ ${ }^{\mathrm{b}}$ CONICET, Engineering Faculty, National University of Cuyo, Argentina \\ c CONICET, LEMIT, Engineering Faculty, National University of La Plata, Argentina \\ d CIC, LEMIT, Engineering Faculty, National University of La Plata, Argentina
}

A R T I C L E I N F O

\section{Keywords:}

High strength concrete

Steel fibers

Blast response

Spalling

Numerical model

\begin{abstract}
A B S T R A C T
High Strength Fiber Reinforced Concrete (HSFRC) presents great advantages when compared with conventional concrete under static loads and thus, it constitutes a promising material to withstand extreme loads. The experimental results of blast tests performed on HSFRC slabs including different types of hooked end steel fibers are presented and numerically analyzed in this paper. The numerical simulation was able to reproduce the experimental results and it confirms that for the same fiber content, shorter fibers provide greater blast resistance, showing smaller craters and spalling at the back face.
\end{abstract}

\section{Introduction}

The addition of fibers to concrete allows reducing its brittle nature and leads to a notable increase in energy absorption capacity. High Strength Fiber Reinforced Concrete (HSFRC) [1] and Ultra High Performance Fiber Reinforced Concrete (UHPFRC) [2] present great advantages for withstanding extreme actions when compared with conventional concrete and constitute promising materials for protective structures that help save lives improving the strength and durability of buildings and infrastructure under extreme loads. Even though the available experimental results show their potential applications, more research is required to improve the understanding of their behavior and to assess their response under extreme actions like blast loads. Studies on the behavior of HSFRC [3] and UHPFRC [4] under high strain rate loads are still limited [5].

The benefits in damage control, accelerations and displacements in HSFRC elements when comparing them to conventional concrete elements have been confirmed [6]. Higher ductility [7,8], lower permanent deformation [7], higher load bearing capacity [8], crack control [8] and greater ability to absorb energy without fragmentation [7-9] than conventional concrete panels were also found in the case of UHPFRC panels exposed to blast loads.

Available experimental results show that blast resistance increases with the increase of fiber volume and that different types of steel fibers have similar effects improving blast strength $[9,10]$. Fibers addition can prevent concrete spalling from slabs rear face and cracks on slab front face [11]. The panels are less likely to fail and they present higher strength with greater extension of damage than conventional concrete specimens due to micro cracking [12]. Multiple failure modes are observed including matrix and aggregates cracking, aggregate/matrix and fiber/matrix debonding and fibers pull-out [12].

The results of blast tests made on HSFRC and UHPFRC elements under close or contact explosions are very scarce [13-15] and available empirical methods [16] are not able to accurately predict spalling damage [13]. More tests are required for a better understanding of HSFRC and UHPFRC performance under blast loads and to assess the effect of different types and contents of fibers on blast response and blast damage. Moreover, taking into account the complexity of HSFRC and UHPFRC behavior combined with that of impact and blast loads, a deep knowledge of the material behavior together with material models and robust numerical tools are required for a proper design of elements under extreme actions.

Available models for the simulation of fiber reinforced materials can be classified in macro and meso-models. In macro-models the composite behavior is represented as a unique homogeneous material with average properties [17-19]. Constitutive laws and material parameters are directly obtained from tests. The main advantage of these models is the use of material information that is relevant for the structural scale. The main disadvantage is the need of performing several tests since the contribution of the fibers is not explicitly considered. This drawback

\footnotetext{
* Corresponding author.

E-mail address: bluccioni@herrera.unt.edu.ar (B. Luccioni).

URL: http://www.herrera.unt.edu.ar/iest (B. Luccioni).
} 
Table 1

Blast tests description.

\begin{tabular}{|c|c|c|c|}
\hline \multirow[t]{2}{*}{ Test type } & Test 1 & Test 2 & Test 3 \\
\hline & & & \\
\hline $\mathrm{TNT}_{\mathrm{eq}}$ mass $[\mathrm{kg}]$ & 0.049 & 0.244 & 0.488 \\
\hline Height $^{\mathrm{a}}[\mathrm{m}]$ & 0.0175 & 0.2425 & 0.2725 \\
\hline
\end{tabular}

a Explosive gravity center height over slab (m).

can be avoided using models derived in the meso-scale that explicitly take into account matrix, fibers, and interface collaboration. The counterpart is that they are computationally expensive. Thus, multiscale approaches $[20,21]$ are normally used to represent the composite behavior at the macro-scale. There are very few models adequate for the simulation of UHPFRC under impact or blast loads [22]. Except for a few models $[10,23]$, most meso-models and multiscale models have been developed and calibrated for static loads and do not take into account the strain rate effect on the components and on the fibers pullout behavior. The response of HSFRC to impact and blast loads is usually simulated with explicit codes like hydrocodes using available macro-models that were originally developed for concrete [24]. The analysis of fibers contribution and the effect of fibers geometry on mechanical properties can contribute reducing the required number of tests to calibrate these homogeneous models.

This paper presents the experimental and numerical analysis of blast tests performed on HSFRC slabs incorporating different types and contents of steel fibers in a High Strength Concrete (HSC) matrix. The role of fibers controlling cracking, scabbing and spalling under close in explosions is clearly shown. Based on the comparison of numerical and experimental results, some recommendations for the numerical simulation of blast loads on HSFRC using homogeneous equivalent models originally developed for concrete are also provided.

\section{Experimental}

\subsection{Blast tests description}

Three different types of blast tests (see Table 1) were performed on HSFRC slabs varying the explosive masses and stand-off distances. The square slabs of $550 \mathrm{~mm}$ side and $50 \mathrm{~mm}$ thickness were supported on a highly reinforced steel frame leaving a free span of $460 \mathrm{~mm}$. The frame has $\mathrm{L}$ shape plates at the corners to prevent the slabs going upwards due to the negative phase of the blast wave. A gel-like explosive formed by a

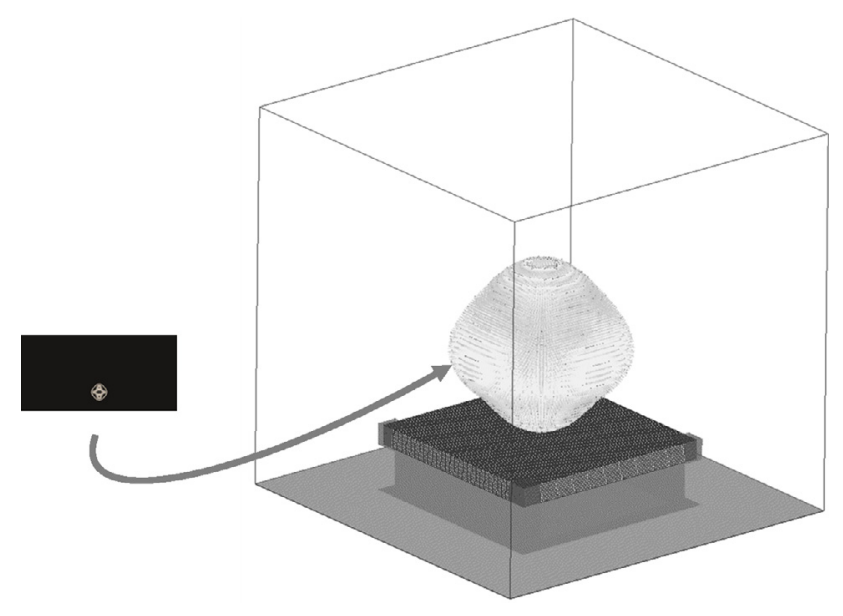

Fig. 1. Numerical model of the blast tests.

semi-plastic mass consisting of a gelatin nitroglycerine and nitrocellulose incorporating ammonium salts and additives was used for the blast tests. It has a nominal TNT equivalence of 0.65 in weight. In all cases, the explosive had cylindrical shape and the detonator was located in the center of the upper surface. In blast Tests 1 the explosive was on the slab while in Tests 2 and 3 the explosive was supported on an expanded polystyrene block. Blast pressures time histories resulting from different amounts of explosive were recorded using pressure sensors (Honeywell 180PC) in order to verify the TNT equivalence of the commercial explosive used in the tests. The pressure sensors were located at 15 and $18 \mathrm{~m}$ from the explosive and at $1 \mathrm{~m}$ height from the ground surface [25]. The minimum standoff distance of $15 \mathrm{~m}$ was defined in order to not exceed the pressure range of the sensors. The sampling rate was 50,000 points per second.

Table 2

Concretes: type and content of fibers and mechanical properties.

\begin{tabular}{llllll}
\hline Concrete type & $\mathrm{P}$ & $\mathrm{L}_{30}-40$ & $\mathrm{~L}_{30}-80$ & $\mathrm{~L}_{60}-40$ & $\mathrm{~L}_{60}-80$ \\
\hline Fibers & & $\mathrm{L}_{30}$ & $\mathrm{~L}_{30}$ & $\mathrm{~L}_{60}$ & $\mathrm{~L}_{60}$ \\
Fibers length [mm] & & 30 & 30 & 60 & 60 \\
Fibers diameter [mm] & & 0.38 & 0.38 & 0.75 & 0.75 \\
Fiber content [kg/m] - volume [\%] & & $40-0.5$ & $80-1.0$ & $40-0.5$ & $80-1.0$ \\
$f_{\mathrm{L}}[\mathrm{MPa}]$ & $7.6(0.5)$ & $7.6(0.6)$ & $8.4(0.6)$ & $7.6(0.9)$ & $7.6(0.9)$ \\
$f_{\max }[\mathrm{MPa}]$ & $7.6(0.5)$ & $11.1(2.2)$ & $15.9(1.1)$ & $12.0(3.6)$ & $18.5(2.3)$ \\
$f_{\mathrm{R} 1}[\mathrm{MPa}]$ & - & $7.3(2.8)$ & $13.1(0.2)$ & $7.0(2.4)$ & $13.9(1.7)$ \\
$f_{\mathrm{R} 3}[\mathrm{MPa}]$ & - & $9.6(3.5)$ & $14.5(1.8)$ & $11.3(3.4)$ & $17.6(2.2)$ \\
fibers/mm & - & $0.016(0.004)$ & $0.039(0.002)$ & $0.009(0.004)$ & $0.019(0.002)$ \\
FRC class [27] & - & $7 \mathrm{e}$ & $13 \mathrm{~d}$ & $7 \mathrm{e}$ & $13 \mathrm{~d}$ \\
\hline
\end{tabular}

(*) Average (standard deviation). 
Table 3

Material properties used for Air and TNT.

\begin{tabular}{llll}
\hline $\begin{array}{l}\text { Air } \\
\text { Equation of state: ideal gas }\end{array}$ & & $\begin{array}{l}\text { TNT } \\
\text { Equation of state: JWL }\end{array}$ \\
\hline Reference density $\left[\mathrm{g} / \mathrm{cm}^{3}\right]$ & $1.22500 \mathrm{E}-3$ & Reference density $\left[\mathrm{g} / \mathrm{cm}^{3}\right]$ & $1.63000 \mathrm{E}+0$ \\
Gamma & $1.40000 \mathrm{E}+0$ & Parameter A $[\mathrm{kPa}]$ & $3.73770 \mathrm{E}+8$ \\
Adiabatic constant & $0.00000 \mathrm{E}+0$ & Parameter B $[\mathrm{kPa}]$ & $3.74710 \mathrm{E}+6$ \\
Pressure shift $[\mathrm{kPa}]$ & $0.00000 \mathrm{E}+0$ & Parameter R1 & $4.15000 \mathrm{E}+0$ \\
Refer. temperature $[\mathrm{T}]$ & $2.88200 \mathrm{E}+2$ & Parameter R2 & $9.00000 \mathrm{E}-1$ \\
Specific heat $[\mathrm{J} / \mathrm{kg} \mathrm{K}]$ & $7.17600 \mathrm{E}+2$ & Parameter W & $3.50000 \mathrm{E}-1$ \\
Thermal Conduc. $[\mathrm{J} / \mathrm{mK} \mathrm{s}]$ & $0.00000 \mathrm{E}+0$ & $\mathrm{C}-\mathrm{J}$ Detonation velocity $[\mathrm{m} / \mathrm{s}]$ & $6.93000 \mathrm{E}+3$ \\
& & C-J Energy/unit vol. $\left[\mathrm{kJ} / \mathrm{m}^{3}\right]$ & $6.00000 \mathrm{E}+6$ \\
& & C-J pressure $[\mathrm{kPa}]$ & $2.10000 \mathrm{E}+7$ \\
& & Burn on compression fraction & $0.00000 \mathrm{E}+0$ \\
& & Pre-burn bulk modulus $[\mathrm{kPa}]$ & $0.00000 \mathrm{E}+0$ \\
& & Adiabatic constant & $0.00000 \mathrm{E}+0$ \\
& & Auto-convert to ideal gas & Yes \\
\hline
\end{tabular}

\subsection{Material and mixtures characterization}

Five High Strength Concretes were studied: a plain concrete (P) and four HSFRC varying the fiber length $(30$ and $60 \mathrm{~mm}$ ) and the fiber dosages ( 40 and $80 \mathrm{~kg} / \mathrm{m}^{3}$ ), see Table 2 . All concretes were prepared using the same base self-compacting matrix. Ordinary Portland cement, silica fume, calcareous filler, natural siliceous sand and $12 \mathrm{~mm}$ maximum size granitic crushed stone were used as component materials. A set retarding plasticizer and a high range water reducer were used as chemical admixtures. The water/(cement + silica fume) ratio was equal to 0.24 .

Two types of hooked-end high carbon steel fibers $\left(\mathrm{L}_{30}\right.$ and $\left.\mathrm{L}_{60}\right)$ with different lengths $(30$ and $60 \mathrm{~mm})$ and diameters $(0.38$ and $0.75 \mathrm{~mm}$ respectively) were used, see Table 2 . The tensile strength of the fibers was over $2500 \mathrm{MPa}$. HSFRC are identified with the name of the fiber followed by the fiber content $\left(\mathrm{L}_{30}-40, \mathrm{~L}_{30}-80, \mathrm{~L}_{60}-40, \mathrm{~L}_{60}-80\right)$. As fibers $\mathrm{L}_{30}$ are shorter, for the same nominal fiber content, HSFRC $\mathrm{L}_{30}-40$ and $\mathrm{L}_{30}-80$ have higher fibers density than concretes incorporating fibers $\mathrm{L}_{60}$.

Four prisms of $430 \mathrm{~mm} \times 50 \mathrm{~mm} \times 105 \mathrm{~mm}$ for bending characterization (with thickness comparable to the slabs), as well as four $100 \mathrm{~mm} \times 200 \mathrm{~mm}$ cylinders to evaluate the compression strength and the static elastic modulus were cast. Major details of the tests performed for material characterization have been previously published [25]. Mean values of $114 \mathrm{MPa}$ and $40 \mathrm{GPa}$ were obtained for the compression strength and the elastic modulus respectively. Bending tests were performed following the guidelines of EN 14651 standard [26]. The prisms had a notch of approximately $19 \mathrm{~mm}$ in the central section and were tested under three points loading. The crack mouth opening displacement (CMOD) was registered and the first peak stress $\left(f_{\mathrm{L}}\right)$, the maximum stress $\left(f_{\max }\right)$ and two residual stresses $\left(f_{\mathrm{R} 1}, f_{\mathrm{R} 3}\right)$ were calculated. After the tests, the number of fibers crossing the central section was counted. The average results and the standard deviation are presented in Table 2. The Fiber Reinforced Concrete (FRC) class, based on the criterion proposed by fib Model Code 2010 [27] is also included.

\section{Numerical simulation}

The experimental tests were designed based on a preliminary numerical simulation with AUTODYN [28] assuming HSFRC as a homogeneous material. After the tests, the dependence of HSFRC mechanical parameters on fiber type and content was studied. Then, the blast tests were numerically modeled in order to analyze the effect of fiber type and content on slabs behavior under close in or contact blast loads and to corroborate the models and material parameters previously assumed.

\subsection{Simulation of blast tests on slabs}

In order to reproduce the complete problem, the numerical model consisted of the air volume, where the slabs were immersed and the blast wave was generated and propagated, the slabs and the support, see Fig. 1. The problem was simulated from the beginning, including explosive detonation, blast wave propagation in air and its interaction with the slabs.

In all cases, the mesh was refined until negligible differences in pressure and impulse values on the plate were found. In the case of elevated blast charges, the explosion was simulated from the detonation instant in a very refined mesh (mesh size $=1.5 \mathrm{~mm}<$ minimum explosive dimension/20) representing the explosive charge and the surrounding air. Before the pressure wave reached the borders of this first model, the results were mapped on a coarser model including the slab (Fig. 1). An axial symmetric mesh and an Euler Gudunov processor were used for the first step of the numerical simulation. The ideal gas equation of state (EOS) was used for the air while JWL EOS was used for TNT. Standard material parameters available in AUTODYN material library were used for air and TNT [29]; they are presented in Table 3. In order to simulate a free field explosion, flow out of air was allowed in all the model borders. The detonation of the explosive was initiated on the top of the cylindrical explosive charge axis as in the tests. An Euler FCT processor with a mesh size of $5 \mathrm{~mm}$ in the surroundings of the plate $(120 \times 120 \times 70$ elements $)$ was used to model air in the second 3D model including the slab. In the case of contact explosions, the problem was modeled from the beginning (explosive detonation) with a $3 \mathrm{D}$ model and using an Euler Godunov processor.

The slabs were modeled using a Lagrange processor and 3D solid elements while shell elements were used for the supports. Mesh refinement was carried out reducing mesh size in uniform meshes until the differences in the results of the maximum vertical displacement of the slab center and the deformed pattern were negligible. To avoid the problem of erosion limit depending on mesh size a slab that does not present failure or erosion was used for this study. Finally, an element size of $5 \mathrm{~mm}(110 \times 110 \times 10$ elements $)$ was used for the slab in all the simulations.

Euler Lagrange interaction was defined between air and the slab and the supports. The fully automatic Euler Lagrange coupling option in AUTODYN was used for this purpose. This coupling algorithm finds the intersection between the external faces of the interacting structures and the cells and faces of the Euler grids. The Euler cells intersected by the Lagrange interface act as a pressure boundary for the Lagrange grid while the Lagrange grid acts as a flow constraint for the material in the Euler mesh. Pressures are integrated over Lagrange surface areas to obtain nodal forces. No friction between Lagrange and Euler parts is considered. 


\subsection{Material models}

Concrete RHT model [30] in combination with p- $\alpha$ equation of state (EOS) [31] was used for HSC and HSFRC. Based on experimental results, the effect of adding different steel fibers and fibers contents was taken into account modifying the main parameters related to tension and shear strength and ductility (failure strain) according to material characterization tests. RHT model was originally developed for concrete so its use for HSFRC requires some analysis and it is not straightforward if general usage rules are expected to be obtained. In fact, the main objective of these simulations was to prove the ability of RHT model to simulate HSFRC blast behavior, to analyze the effect of steel fibers addition on material parameters and to discuss how the different material parameters affect blast response.

p- $\alpha$ EOS [31] has been proved to be capable of representing well the concrete thermodynamic behavior at high pressures and it also allows for a reasonably detailed description of the compaction behavior at low pressure ranges [32]. The equation of state of the fully compacted or solid material is described with a polynomial function as,

$p=A_{1} \mu+A_{2} \mu^{2}+A_{3} \mu^{3}+\left(B_{0}+B_{1} \mu\right) \rho_{0} e$ for $\mu \geqslant 0$ (compaction)

$p=T_{1} \mu+T_{2} \mu^{2}+B_{0} \rho_{0}$ e for $\mu<0$

$\mu=\frac{\rho}{\rho_{0}}-1$

where $p$ is the hydrostatic pressure, $\rho$ is the density, $\rho_{0}$ is the initial density (at zero pressure), $e$ is the specific internal energy, $\mu$ is the relative volume change and $A_{i}, B_{i}$ and $T_{i}$ are constants.

The EOS for the porous material is calculated substituting $\rho$ by a new variable $\alpha_{p} \rho_{p}$ in Eq. (1). $\rho_{p}$ is the density of the porous material and $\alpha_{p}$ is the material "porosity" that can be defined as

$\alpha_{p}=\rho_{s} / \rho_{p}$

where $\rho_{\mathrm{S}}$ and $\rho_{p}$ refer to the density of the solid and the porous material at the same pressure and temperature respectively. The following definition is used in $p-\alpha$ EOS,

$\alpha_{p}(p)=1+\left(\alpha_{\text {init }}-1\right)\left(\frac{p_{\text {lock }}-p}{p_{\text {lock }}-p_{\text {crush }}}\right)^{n}$

where $\alpha_{\text {init }}$ is the initial porosity of the intact concrete, $p_{\text {crush }}$ corresponds to the pore collapse pressure beyond which concrete plastic compaction occurs, $p_{\text {lock }}$ is the pressure at which the concrete porosity $\alpha_{p}$ reaches unity and $n$ is the compaction exponent.

The RHT strength model [30] is a combined plasticity and shear damage model in which the deviatoric stress $Y=\sqrt{3 J_{2}}$ is limited by a generalized failure surface defined as

$\left(\sqrt{3 J_{2}}\right)_{\text {fail }}=Y_{\text {fail }}\left(p^{*}, \theta, \dot{\varepsilon}\right)=Y_{C}\left(p^{*}\right) r_{3}(\theta) F_{\text {rate }}(\dot{\varepsilon})$

$Y_{C}\left(p^{*}\right)=f_{c}\left[A\left(p^{*}-p_{\text {spall }}^{*} F_{\text {rate }}(\dot{\varepsilon})\right)^{N}\right]$

where $f_{c}$ is the uniaxial compression strength; $A$ and $N$ are material constants; $p^{*}=p / f_{c}$ is the normalized pressure and $p_{\text {spall }}^{*}=f_{t} / f_{c}$, where $f_{t}$ is the uniaxial tension strength; $F_{\text {rate }}(\dot{\varepsilon})$ represents the dynamic amplification factor (DIF) as a function of strain rate $\dot{\varepsilon}$.

$r_{3}(\theta)=\frac{r}{r_{c}}=\frac{2\left(1-\psi^{2}\right) \cos \theta+(2 \psi-1) \sqrt{4\left(1-\psi^{2}\right) \cos ^{2} \theta+5 \psi^{2}-4 \psi}}{4\left(1-\psi^{2}\right) \cos ^{2} \theta+(1-2 \psi)^{2}}$

$\cos 3 \theta=\frac{3 \sqrt{3}}{2} \frac{J_{3}}{\left(J_{2}\right)^{3 / 2}} ; \psi=\frac{r_{t}}{r_{c}}=Q+B Q p^{*} ; 0.5<\psi \leqslant 1$

$J_{2}$ and $J_{3}$ represent the second and the third invariants of the deviatoric stress tensor. The input parameter $Q$ defines the ratio of strength at zero pressure and the coefficient $B Q$ defines the rate at which the intersection of fracture surface with deviatoric planes transitions from an approximately triangular shape to a circular shape with increasing pressure. $F_{\text {rate }}$ takes into account the strain rate enhancement of the deviatoric strength [30]. Different expressions are used for compression and tension with linear interpolation in the intermediate pressure regime.

Compression

$F_{\text {rate }}=\left\{\begin{array}{l}\left(\frac{\dot{\varepsilon}}{\dot{\varepsilon_{0}}}\right)^{\alpha} \text { for } \dot{\varepsilon} \leqslant 30 \mathrm{~s}^{-1} ; \alpha=\frac{1}{5+0.75 f_{c}[\mathrm{MPa}]} ; \dot{\varepsilon}_{0}=30.10^{-6} \mathrm{~s}^{-1} \\ \gamma \sqrt[3]{\dot{\varepsilon}} \text { for } \dot{\varepsilon}>30 \mathrm{~s}^{-1} ; \log \gamma=6 \alpha-0.492\end{array}\right.$

Tension

$F_{\text {rate }}=\left\{\begin{array}{l}\left(\frac{\dot{\varepsilon}}{\dot{\varepsilon}_{0}}\right)^{\delta} \text { for } \dot{\varepsilon} \leqslant 30 s^{-1} ; \delta=\frac{1}{10+0.5 f_{c}[\mathrm{MPa}]} ; \dot{\varepsilon}_{0}=3.10^{-6} \mathrm{~s}^{-1} \\ \eta \sqrt[3]{\dot{\varepsilon}} \text { for } \dot{\varepsilon}>30 s^{-1} ; \log \eta=7 \delta-0.492\end{array}\right.$

$\alpha$ is the compression strain rate exponent and $\delta$ is the tension strain rate exponent.

An elastic limit surface and a "hardening" slope are defined to represent strain hardening. The elastic limit surface is scaled down from the fracture surface

$Y_{\text {elast }}=Y_{\text {fail }}\left(p^{*}\right) F_{\text {elast }} F_{\text {cap }}(p)$

$F_{\text {elast }}$ is the ratio of the elastic strength to failure surface strength derived from two input parameters (elastic compression strength $/ f_{c}$ ) and (elastic tensile strength $/ f_{t}$ ). The model presents the option of including a cap to limit the elastic deviatoric stress under large compressions.

$F_{c a p}(p)=\left\{\begin{array}{l}1 \quad \text { for } p \leqslant p_{u}=\frac{f_{c}}{3} \\ \sqrt{1-\left(\frac{p-p_{u}}{p_{0}-p_{u}}\right)^{2}} \quad \text { for } p_{u}<p<p_{0} \\ 0 \quad \text { for } p \geqslant p_{0}=p_{\text {crush }}\end{array}\right.$

The pre-peak fracture surface is subsequently defined through interpolation between the elastic and fracture surfaces as follows

$$
\begin{aligned}
& Y_{\text {hard }}=Y_{\text {elast }}+\frac{\varepsilon_{\text {pl }}}{\varepsilon_{\text {plpresoft }}}\left(Y_{\text {fail }}-Y_{\text {elast }}\right) \\
& \varepsilon_{\text {plpresoft }}=\frac{Y_{\text {fail }}-Y_{\text {elast }}}{3 G}\left(\frac{G_{\text {elas }}}{G_{\text {elas }}-G_{\text {plas }}}\right)
\end{aligned}
$$

where the "hardening" slope $\left(\frac{G_{\text {elas }}}{G_{\text {elas }}-G_{\text {plas }}}\right)$ is an input parameter.

A residual (frictional) failure surface is defined as,

$Y_{\text {resid }}^{*}=B p^{* M}$

where $B$ is the residual failure surface constant and $M$ is the residual failure surface exponent, both input parameters.

Damage is assumed to accumulate due to inelastic deviatoric straining (shear induced cracking) using the following relationships

Table 4

Material properties used for HSC and HSFRC EOS.

\begin{tabular}{ll}
\hline Equation of state: P alpha & \\
\hline Reference density $\left[\mathrm{g} / \mathrm{cm}^{3}\right]$ & $2.75 \mathrm{E}+0$ \\
Porous density $\left[\mathrm{g} / \mathrm{cm}^{3}\right]$ & $2.52 \mathrm{E}+0$ \\
Porous sound speed $[\mathrm{m} / \mathrm{s}]$ & $2.242 \mathrm{E}+3$ \\
Initial compaction pressure $[\mathrm{kPa}]$ & $9.33 \mathrm{E}+4$ \\
Solid compaction pressure $[\mathrm{kPa}]$ & $6.00 \mathrm{E}+6$ \\
Compaction exponent & $3.00 \mathrm{E}+0$ \\
Solid EOS & Polyn. \\
Bulk modulus $A_{1}[\mathrm{kPa}]$ & $2.20 \mathrm{E}+7$ \\
Parameter $A_{2}[\mathrm{kPa}]$ & $3.958 \mathrm{E}+7$ \\
Parameter $A_{3}[\mathrm{kPa}]$ & $9.04 \mathrm{E}+6$ \\
Parameter $B_{0}$ & $1.22 \mathrm{E}+0$ \\
Parameter $B_{1}$ & $1.22 \mathrm{E}+0$ \\
Parameter $T_{1}[\mathrm{kPa}]$ & $3.527 \mathrm{E}+7$ \\
Parameter $T_{2}[\mathrm{kPa}]$ & $0.00 \mathrm{E}+0$ \\
Compaction curve & Standard
\end{tabular}


Table 5

Material properties used for HSC and HSFRC strength model.

\begin{tabular}{|c|c|c|c|c|c|}
\hline & $\mathrm{P}$ & $\mathrm{L}_{30}-40$ & $\mathrm{~L}_{30}-80$ & $\mathrm{~L}_{60}-40$ & $\mathrm{~L}_{60}-80$ \\
\hline Shear modulus [kPa] & $1.65 \mathrm{E}+7$ & $1.65 \mathrm{E}+7$ & $1.65 \mathrm{E}+7$ & $1.65 \mathrm{E}+7$ & $1.65 \mathrm{E}+7$ \\
\hline Comp. strength $\left(f_{c}\right)[\mathrm{kPa}]$ & $1.14 \mathrm{E}+5$ & $1.14 \mathrm{E}+5$ & $1.14 \mathrm{E}+5$ & $1.14 \mathrm{E}+5$ & $1.14 \mathrm{E}+5$ \\
\hline Tens. strength $\left(f_{t} / f_{c}\right)$ & $4.50 \mathrm{E}-2$ & $5.00 \mathrm{E}-2$ & $9.90 \mathrm{E}-2$ & $5.50 \mathrm{E}-2$ & $1.03 \mathrm{E}-1$ \\
\hline Shear strength $\left(f_{s} / f_{c}\right)$ & $8.10 \mathrm{E}-2$ & $9.00 \mathrm{E}-2$ & $1.78 \mathrm{E}-1$ & $1.00 \mathrm{E}-1$ & $1.86 \mathrm{E}-1$ \\
\hline Intact failure surface constant $A$ & $1.60 \mathrm{E}+0$ & $1.60 \mathrm{E}+0$ & $1.60 \mathrm{E}+0$ & $1.60 \mathrm{E}+0$ & $1.60 \mathrm{E}+0$ \\
\hline Intact failure surface exponent $N$ & $6.10 \mathrm{E}-1$ & $6.10 \mathrm{E}-1$ & $6.10 \mathrm{E}-1$ & $6.10 \mathrm{E}-1$ & $6.10 \mathrm{E}-1$ \\
\hline Tens./Comp. Meridian ratio $(Q)$ & $6.805 \mathrm{E}-1$ & $6.805 \mathrm{E}-1$ & $6.805 \mathrm{E}-1$ & $6.805 \mathrm{E}-1$ & $6.805 \mathrm{E}-1$ \\
\hline Brittle to duct trans. & $1.050 \mathrm{E}-2$ & $1.050 \mathrm{E}-2$ & $1.050 \mathrm{E}-2$ & $1.050 \mathrm{E}-2$ & $1.050 \mathrm{E}-2$ \\
\hline$G$ (elas.)/(elas.-plas.) & $2.00 \mathrm{E}+0$ & $2.00 \mathrm{E}+0$ & $2.00 \mathrm{E}+0$ & $2.00 \mathrm{E}+0$ & $2.00 \mathrm{E}+0$ \\
\hline Elastic strength $/ f_{t}$ & $7.00 \mathrm{E}-1$ & $7.00 \mathrm{E}-1$ & $7.00 \mathrm{E}-1$ & $7.00 \mathrm{E}-1$ & $7.00 \mathrm{E}-1$ \\
\hline Elastic strength $/ f_{c}$ & $5.30 \mathrm{E}-1$ & $5.30 \mathrm{E}-1$ & $5.30 \mathrm{E}-1$ & $5.30 \mathrm{E}-1$ & $5.30 \mathrm{E}-1$ \\
\hline Frac. strength cons $B$ & $1.60 \mathrm{E}+0$ & $1.60 \mathrm{E}+0$ & $1.60 \mathrm{E}+0$ & $1.60 \mathrm{E}+0$ & $1.60 \mathrm{E}+0$ \\
\hline Frac. strength exp. $M$ & $6.10 \mathrm{E}-1$ & $6.10 \mathrm{E}-1$ & $6.10 \mathrm{E}-1$ & $6.10 \mathrm{E}-1$ & $6.10 \mathrm{E}-1$ \\
\hline Comp. str. rate exp. & 0.011 & 0.011 & 0.011 & 0.011 & 0.011 \\
\hline Tens strain rate exp. & 0.015 & 0.015 & 0.015 & 0.015 & 0.015 \\
\hline CAP on elastic surf? & Yes & Yes & Yes & Yes & Yes \\
\hline \multicolumn{6}{|l|}{ Failure: $R H T$ concrete } \\
\hline Damage constant, $D_{1}$ & $4.00 \mathrm{E}-2$ & $4.00 \mathrm{E}-2$ & $4.00 \mathrm{E}-2$ & $4.00 \mathrm{E}-2$ & $4.00 \mathrm{E}-2$ \\
\hline Damage constant, $D_{2}$ & $1.00 \mathrm{E}+0$ & $1.00 \mathrm{E}+0$ & $1.00 \mathrm{E}+0$ & $1.00 \mathrm{E}+0$ & $1.00 \mathrm{E}+0$ \\
\hline Min. strain to failure & $5.00 \mathrm{E}-3$ & $1.50 \mathrm{E}-2$ & $4.00 \mathrm{E}-2$ & $1.50 \mathrm{E}-2$ & $4.00 \mathrm{E}-2$ \\
\hline Residual shear mod. fraction & $1.30 \mathrm{E}-1$ & $1.30 \mathrm{E}-1$ & $1.30 \mathrm{E}-1$ & $1.30 \mathrm{E}-1$ & $1.30 \mathrm{E}-1$ \\
\hline Tensile failure & Hydro tensi & & & & \\
\hline \multicolumn{6}{|l|}{ Erosion: instantaneous geom. Strain } \\
\hline Erosion strain & 0.1 & 1.0 & 1.0 & 1.0 & 1.0 \\
\hline \multicolumn{6}{|c|}{ Only for contact blast on HSFRC. Elastic/failure: hydro tensile limit(pmin) } \\
\hline Erosion: Inst. Geom. Strain & & 0.5 & 0.5 & 0.1 & 0.1 \\
\hline
\end{tabular}

$$
\begin{aligned}
& D=\int_{0}^{\varepsilon_{p}} \frac{d \varepsilon_{p}}{\varepsilon_{p}^{\text {fail }}} \text { for } \varepsilon_{p}^{\text {fail }}>\varepsilon_{f}^{\text {min }} \text { with } \varepsilon_{p}^{\text {fail }}=D_{1}\left(p^{*}-p_{\text {spall }}^{*}\right)^{D_{2}} \\
& D=\int_{0}^{\varepsilon_{p}} \frac{d \varepsilon_{p}}{\varepsilon_{f}^{\text {min }}} \text { for } \varepsilon_{p}^{\text {fail }} \leqslant \varepsilon_{f}^{\text {min }}
\end{aligned}
$$

where $D_{1}$ and $D_{2}$ are material constants and $\varepsilon_{f}^{\min }$ is the minimum strain to failure. Damage accumulation can have two effects on the model:

- Strain softening (reduction in strength). The current fracture surface (for a given level of damage) is scaled down from the intact surface

$Y_{\text {fract }}^{*}=(1-D) Y_{\text {fail }}^{*}+D Y_{\text {resid }}^{*}$

- Reduction in shear stiffness

$G_{\text {frac }}+(1-D) G_{\text {elas }}+D G_{\text {resid }}$

Geometric strain erosion model was used for HSC and HSFRC. Erosion is initiated when geometric strain limit is reached

$$
\begin{aligned}
& \varepsilon_{\text {eff }}=\left(\varepsilon_{\text {eff }}\right)_{l i m} \\
& \varepsilon_{\text {eff }}=\frac{2}{3} \sqrt{\varepsilon_{x x}^{2}+\varepsilon_{y y}^{2}+\varepsilon_{z z}^{2}-\left(\varepsilon_{x x} \varepsilon_{y y}+\varepsilon_{x x} \varepsilon_{z z}+\varepsilon_{y y} \varepsilon_{z z}\right)+3\left(\varepsilon_{x y}^{2}+\varepsilon_{x z}^{2}+\varepsilon_{y z}^{2}\right)}
\end{aligned}
$$

All the parameters used for plain concrete (HSC) and HSFRC are presented in Tables 4 and 5. HSC and HSFRC compression strength and elasticity modulus were obtained from static uniaxial compression tests. According to the experimental results, the same value of compression strength was used for the five materials tested. For the fibers contents used in these experiments, stiffness is not affected by the incorporation of fibers, thus the same shear modulus was used for the five materials. Tension strength and minimum strain to failure were indirectly obtained from static flexure tests numerical simulation [33] and comparison with experimental results (Table 2). It is well known that fibers addition improves the apparent tension strength of HSFRC. The increment in tension strength with fiber content is clear in Table 5. The shear/compression strength ratio of HSFRC was scaled with the same factor than tension/compression strength HSFRC. HSC presents brittle failure. In accordance with the suggestion of Tu and $\mathrm{Lu}$ [32] a small value (0.005) of minimum strain to failure was obtained for HSC. Nevertheless, it should be observed that in the case of brittle failure this value is not a material property but depends on the mesh size. HSFRC presents a more ductile flexure response and this fact is evident in the values of minimum strain to failure obtained from calibration of flexure tests. In RHT model, the tensile behavior of the material is described by a plasticity-damage tensile failure model (see Eqs. (14) and (15)). Some
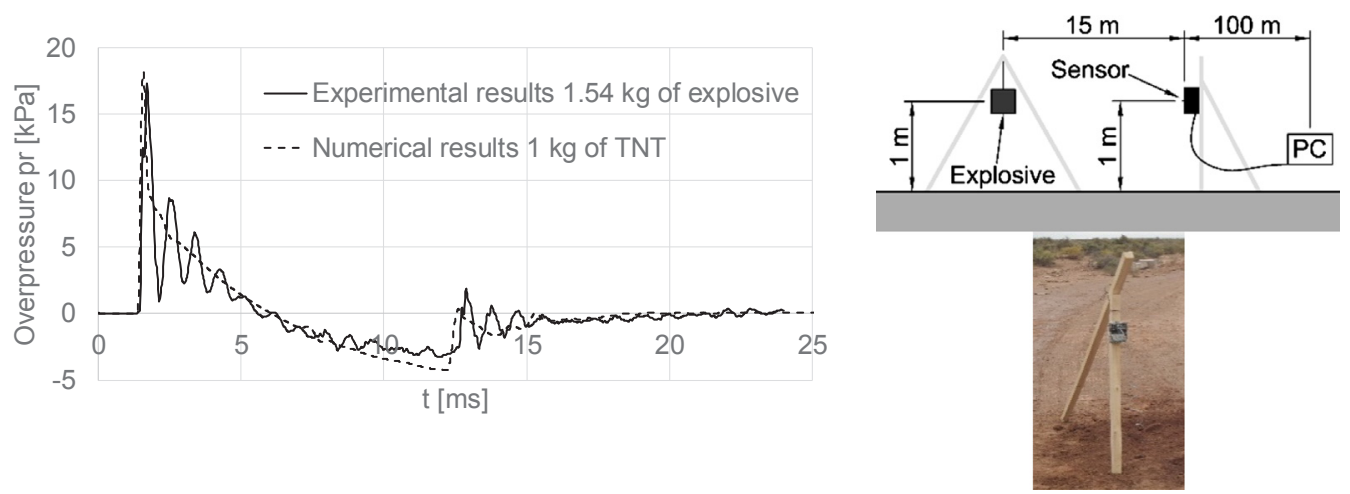

Fig. 2. Pressure time-history at $15 \mathrm{~m}$ from the explosive. Comparison of experimental (1.54 kg of explosive) and numerical (1 kg TNT) results. 
Face

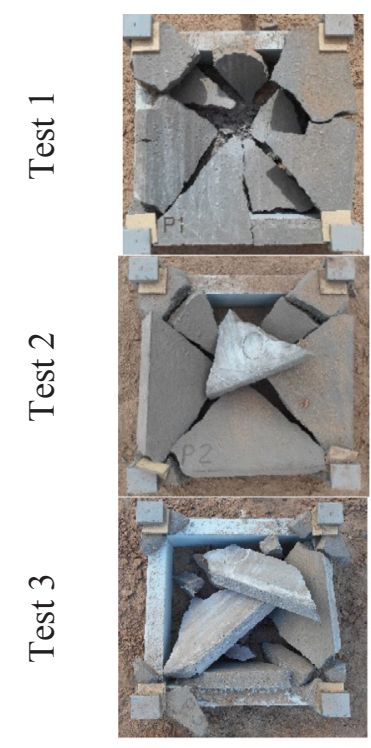

Front
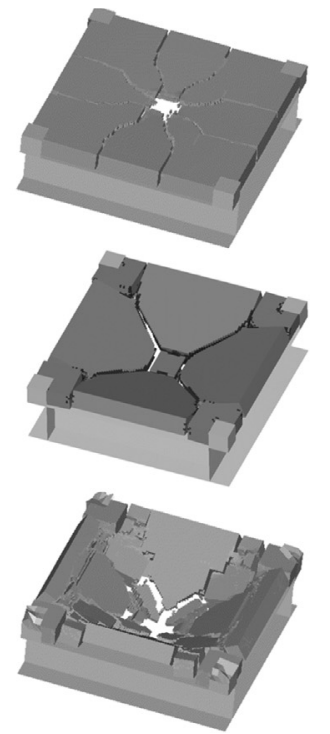

Rear

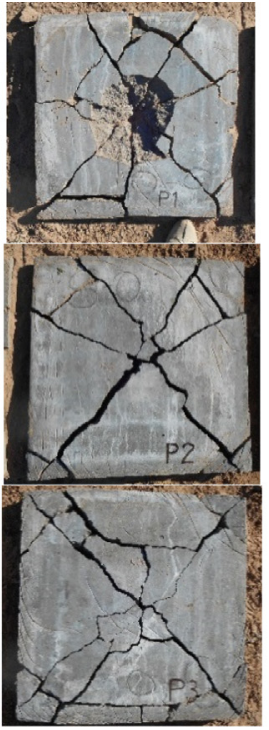

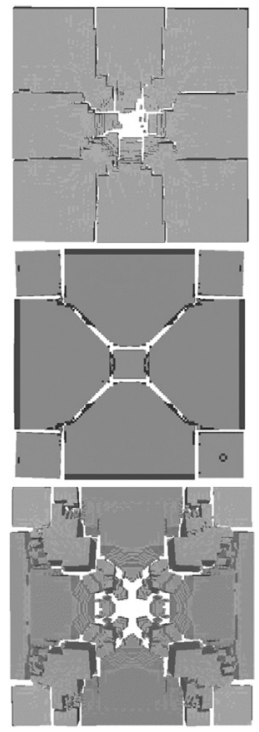

Fig. 3. Experimental results and numerical simulation of $\mathrm{P}$ slabs blast tests.

papers [32,34] have pointed out the limitations of this model for concrete tensile behavior and probably it also presents limitations for HSFRC. The shape of the tension strain softening curve surely can affect the results but its effect is stronger on the time history response than on the damage patterns analyzed in this paper. Further research is needed concerning the proper strain-softening model for HSFRC.

Although some tests have been made to evaluate the response of HSFRC and the fibers contribution under high strain rate, the results are still contradictory [5]. There is not enough information concerning the role of fibers in the dynamic response of HSFRC at high strain rates $[35,36]$. Strain rate dependency was modeled using standard DIF functions available for plain concrete $[28,30]$. The values of the strain rate exponents were calculated as a function of the compression strength and they are presented in Table 4. Erosion limits were calibrated to reproduce experimental result from blast tests, they are included in Table 4 and they will be later discussed. Standard values for
HSC [28] were used for the rest of the parameters of HSC and HSFRC and they are also included in Tables 4 and 5.

The soil was modeled as an elastic medium. Johnson - Cook model was used for the high strength steel supports.

\section{Results and discussion}

\subsection{Experimental results}

The overpressure recorded in a pressure sensor located at $15 \mathrm{~m}$ from an explosion of $1.54 \mathrm{~kg}$ of explosive elevated $1.0 \mathrm{~m}$ over the ground [36] is presented in Fig. 2 as illustration.

A general view of the damage patterns produced by the different blast tests (types 1, 2 and 3) on front and rear face of the slabs of each concrete are presented in Figs. 3-7. The experimental results are compared with the numerical simulations of each test.

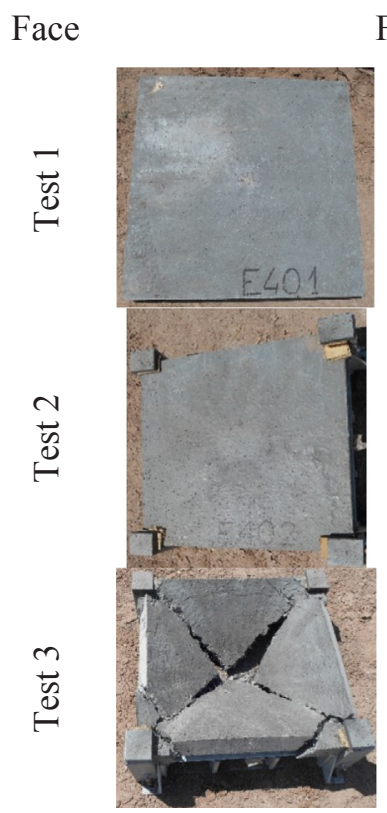

Front
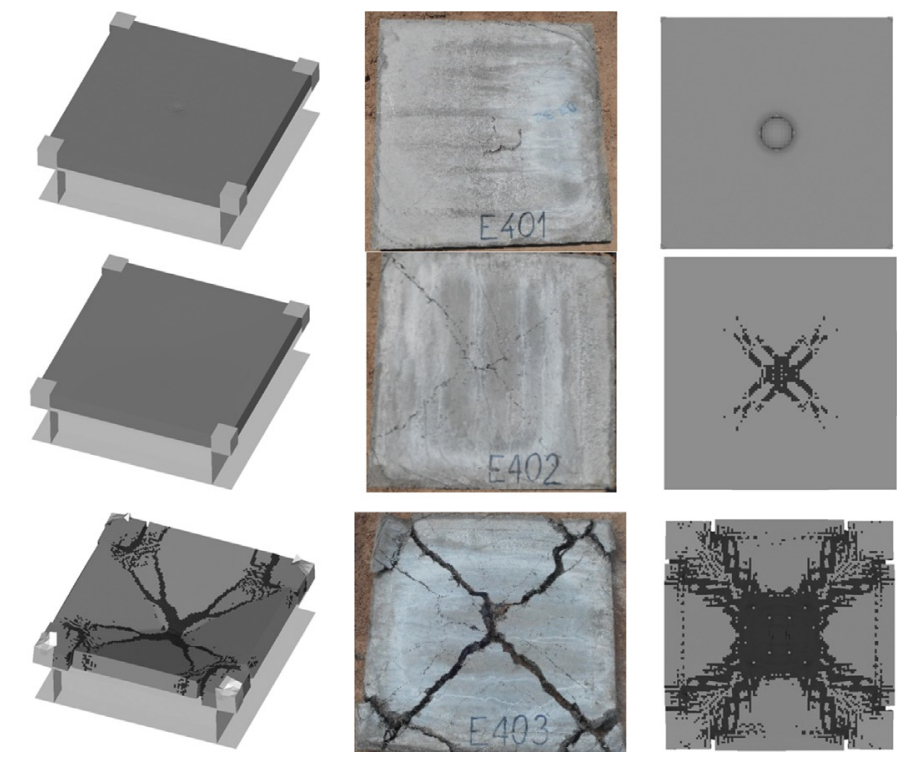

Fig. 4. Experimental results and numerical simulation of $\mathrm{L}_{30}-40$ slabs blast tests. 
Face

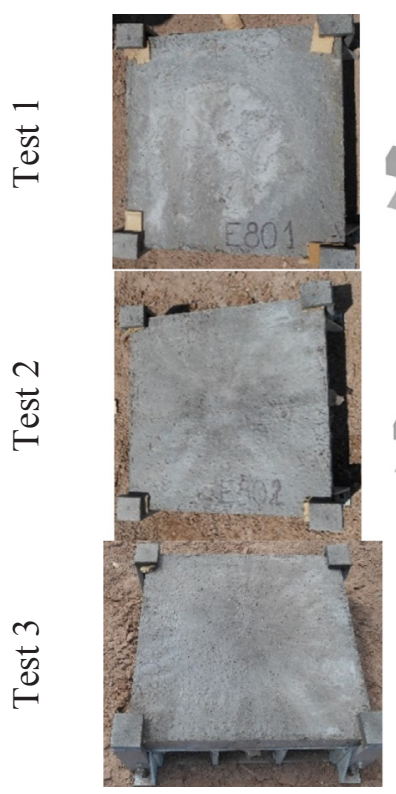

Front
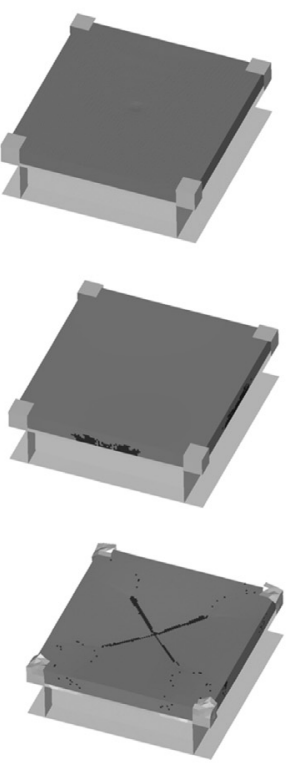
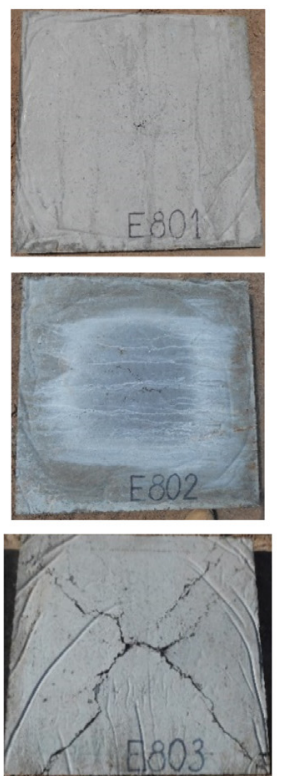

Rear
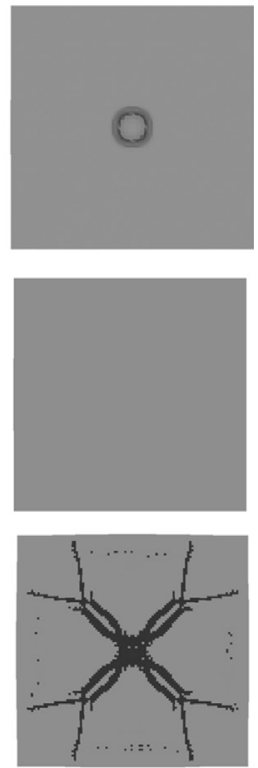

Fig. 5. Experimental results and numerical simulation of $\mathrm{L}_{30}-80$ slabs blast tests.

When a blast load is detonated close to a concrete slab it produces a shock wave that acts on the slab front surface producing high triaxial compression stresses that may cause material local failure [16] characterized by a crater. Part of the blast wave energy is reflected and the other part is propagated through the slab thickness. When this wave reaches the rear surface, a new reflection of the compression wave occurs originating a tension rebound from the rear face that can cause concrete spalling and particle ejection at the rear face. Theoretical analysis of the spall damage is quite complex. If the explosive is detonated at a greater distance, it could cause flexure failure. If the stand-off distance is reduced a localized punching shear failure can take place before the slab can respond in flexural mode. The blast tests results clearly show these different types of concrete failure and the effect of the addition of fibers.

In all tests performed on plain concrete brittle flexure failure of the slabs was observed regardless of the explosive mass and stand-off distance (see Fig. 3). Some of the slabs fragments had flown out and were lying in the surroundings of the slabs supports. The slabs were completely split in many parts by diagonal fractures. It is also observed that additional fractures appeared near slab corners that were prevented to move by the angles at the steel support corners. Circular fractures typical of clamped plates were also developed (see the reconstructed slabs in Fig. 3). The flexure failure of these slabs, even under small contact blast loads, is explained by the reduced slab thickness and the brittle nature of HSC that was also evidenced in the quasi-static beams response. In the case of blast Test 1 that corresponds to a small contact explosion, flexure failure of plain concrete slab is accompanied by an important concrete spalling at the rear face that reaches the front face. The slab was completely perforated by the blast load, see Fig. 3 .

The damage patterns obtained for HSFRC slabs were strongly

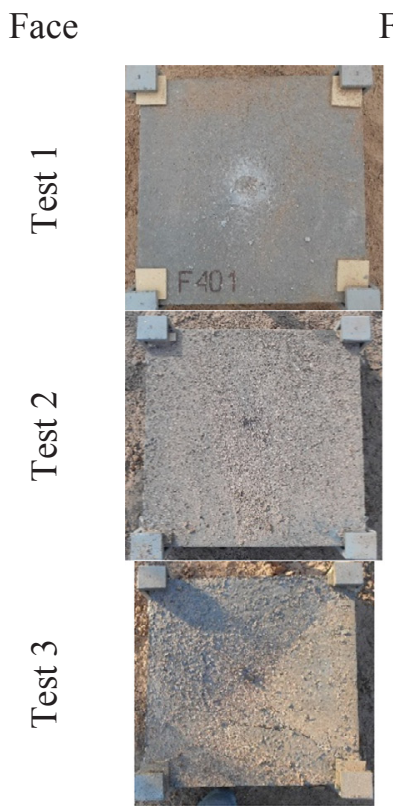

Front

\section{Rear}
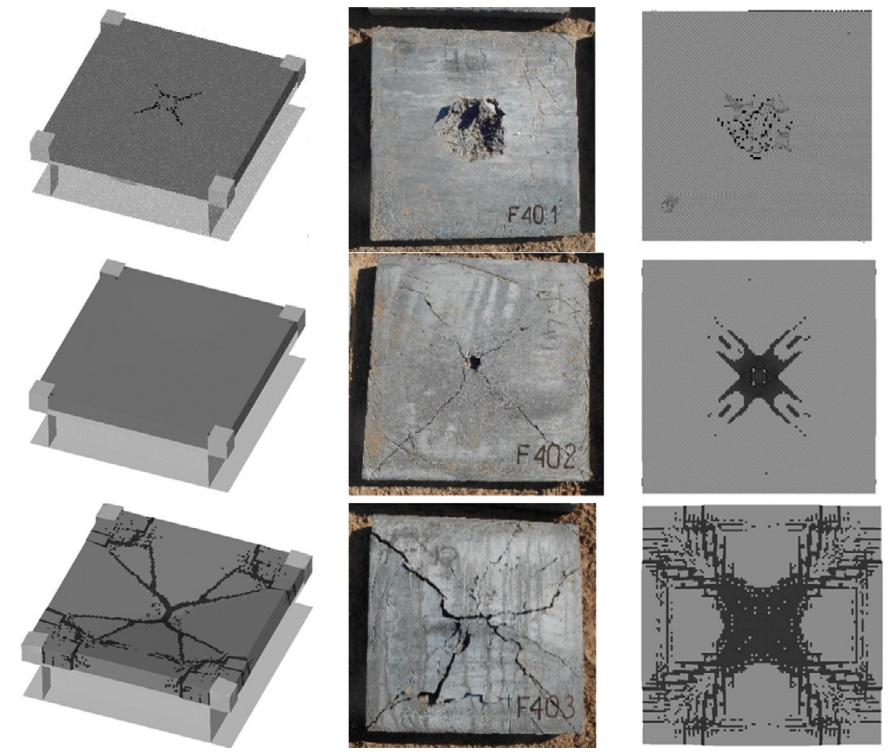

Fig. 6. Experimental results and numerical simulation of $\mathrm{L}_{60}-40$ slabs blast tests. 


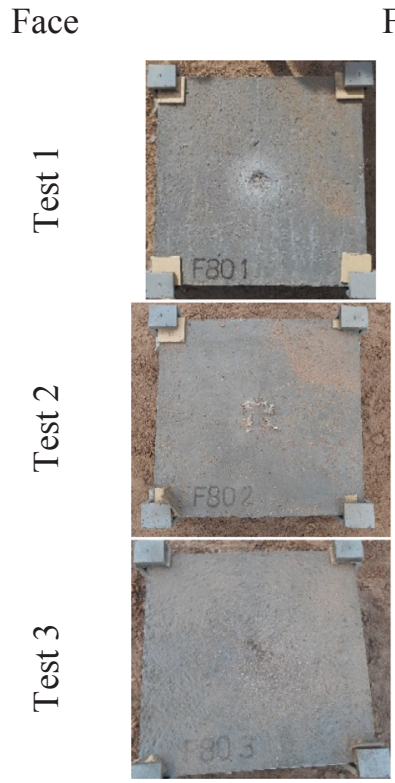

Front

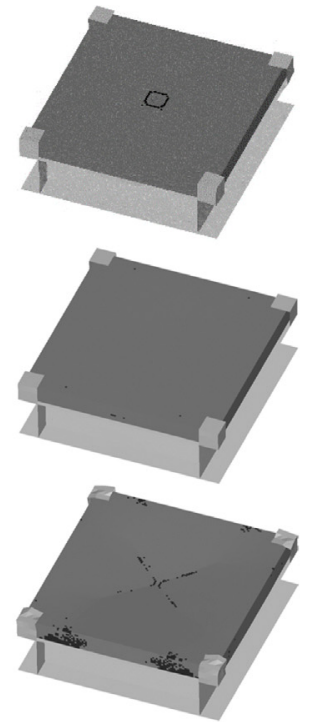

Rear

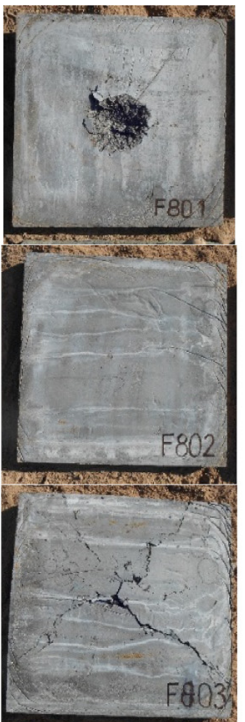

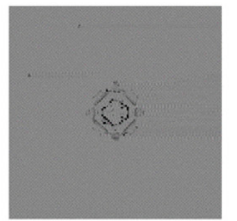
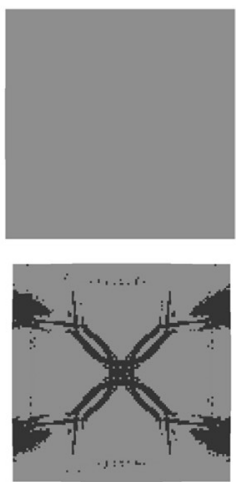

Fig. 7. Experimental results and numerical simulation of $\mathrm{L}^{60} \mathrm{-}_{80}$ slabs blast tests.

Table 6

Dimension of damage area for contact blast.

\begin{tabular}{lllllll}
\hline Results & Slab & $\mathrm{P}$ & $\mathrm{L}_{30}-40$ & $\mathrm{~L}_{30}-80$ & $\mathrm{~L}_{60}-40$ & $\mathrm{~L}_{60}-80$ \\
\hline Crater diameter & Experimental & Fractured & 35 & 32 & 55 & 48 \\
$\quad[\mathrm{~mm}]$ & Numerical & 60 & 40 & 30 & 60 & 45 \\
Spalling diameter & Experimental & 245 & 70 & 25 & 163 & 150 \\
$\quad$ [mm] & Numerical & 200 & 65 & 40 & 150 & 140 \\
\hline
\end{tabular}
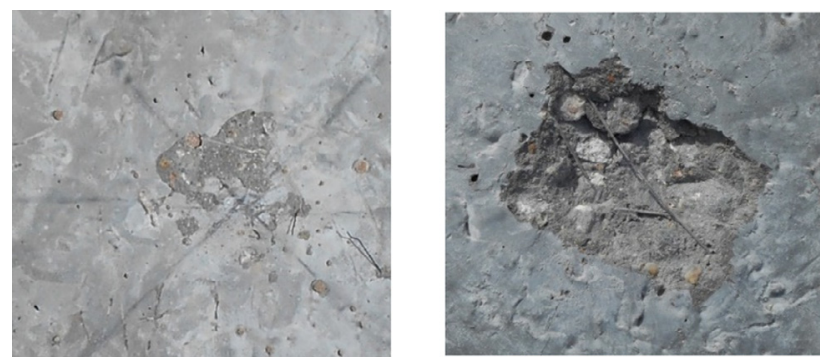

Fig. 8. Eroded zone at front face of slabs $L_{30}-80$ and $L_{60}-80$ after blast Tests 1 .

different from those of P slabs. No HSFRC slabs tested under contact explosions (blast Test 1) exhibited flexure failure and they preserved integrity after the tests (see Figs. 4-7). Flexure cracks can hardly be identified. The front faces of the slabs presented a small eroded zone like a crater produced by the high pressures originated by the detonation of the explosive in contact with concrete.

The dimensions of the craters are presented in Table 6. Zooms of the eroded zone of slabs $\mathrm{L}_{30}-80$ and $\mathrm{L}_{60}-80$ after blast Tests 1 are presented in Fig. 8. In the case of $\mathrm{L}_{30}-80$ the damage is superficial while in $\mathrm{L}_{60}-80$ the fibers can be identified showing that some of the hooks have been straightened. The crater dimensions were reduced when fiber content was increased. However, only a slight reduction of crater dimensions was obtained for fibers $\mathrm{L}_{30}$ when doubling the fiber volume content but the reduction was greater for longer fibers. This result confirms that $0.5 \%$ of fibers $\mathrm{L}_{30}$ content is enough to control cratering. On the other side, all HSFRC slabs subjected to contact explosions presented rear face concrete spalling. Slabs containing fibers $\mathrm{L}_{30}$ (shorter fibers) exhibit smaller craters on front face and spalling on rear face than slabs with fibers $\mathrm{L}_{60}$ with the same fiber content. The spalling zone at the rear face of slabs $\mathrm{L}_{30}-40$ and $\mathrm{L}_{30}-80$ was not completely separated from the slabs.
These results show that for the same fiber content, shorter fibers are more efficient controlling concrete cratering and spalling than longer fibers. This effect can be partly attributed to the fact that for the same fiber content fibers $\mathrm{L}_{30}$ density is greater. Residual deflection of HSFRC slabs under contact blast loads could not be appreciated; all HSFRC slabs remained almost plane.

In blast Test 2 slab $P$ was fractured while $\mathrm{L}_{30^{-}}-40$ and $\mathrm{L}_{60^{-}}-40$ slabs presented flexure cracks at the rear face and slabs $\mathrm{L}_{30}-80$ and $\mathrm{L}_{60}-80$ exhibited almost imperceptible flexure cracks, (see Figs. 4-7). Diagonal cracks were evident on rear face of slabs $\mathrm{L}_{30}-40$ and $\mathrm{L}_{60}-40$ and, in spite of them, the slabs preserved their integrity as fibers crossing the cracks prevented their opening. These cracks are flexure cracks and were evidently caused by the positive phase of the blast wave acting on the front face. Negative phase of the blast wave, that is always smaller than the positive phase, was not enough to crack the front face. The direct pressure acting on the front face produced erosion in a reduced zone while a bigger spalling zone was created in the rear face. Both damaged zones were smaller than those produced by the contact explosion. In contrast with $\mathrm{L}_{60}-40$, slab $\mathrm{L}_{30}-40$ did not exhibit either crater or spalling showing the greater effect of shorter fibers controlling these types of damage. The same explosion type only produced almost imperceptible

Table 7

Maximum cracks widths and residual deflections measured on HSFRC slabs.

\begin{tabular}{lllll}
\hline Slab & & Test 1 & Test 2 & Test 3 \\
\hline $\mathrm{L}_{30}-40$ & Front face & $0.1 \mathrm{~mm}$ & - & Fractured \\
& Rear face & $0.2 \mathrm{~mm}$ & $1.4 \mathrm{~mm}$ & Fractured \\
& Lateral sides & $0.1 \mathrm{~mm}$ & $0.2 \mathrm{~mm}$ & Fractured \\
& Max. residual deflection & - & $2 \mathrm{~mm}$ & $>170 \mathrm{~mm}$ \\
$\mathrm{~L}_{30}-80$ & Front face & $0.05 \mathrm{~mm}$ & - & $0.1 \mathrm{~mm}$ \\
& Rear face & $0.1 \mathrm{~mm}$ & $0.2 \mathrm{~mm}$ & $3.5 \mathrm{~mm}$ \\
& Lateral sides & - & $0.1 \mathrm{~mm}$ & $1.5 \mathrm{~mm}$ \\
& Max. residual deflection & - & $2 \mathrm{~mm}$ & $5 \mathrm{~mm}$ \\
$\mathrm{~L}_{60}-40$ & Front face & $0.1 \mathrm{~mm}$ & $0.1 \mathrm{~mm}$ & $3 \mathrm{~mm}$ \\
& Rear face & $0.3 \mathrm{~mm}$ & $2.5 \mathrm{~mm}$ & $10 \mathrm{~mm}$ \\
& Lateral sides & $0.1 \mathrm{~mm}$ & - & $2 \mathrm{~mm}$ \\
& Max. residual deflection & - & $5 \mathrm{~mm}$ & $27 \mathrm{~mm}$ \\
$\mathrm{~L}_{60}-80$ & Front face & $0.1 \mathrm{~mm}$ & - & $0.1 \mathrm{~mm}$ \\
& Rear face & $0.1 \mathrm{~mm}$ & $0.2 \mathrm{~mm}$ & $4 \mathrm{~mm}$ \\
& Lateral sides & - & - & $1.5 \mathrm{~mm}$ \\
& Max. residual deflection & - & - & $9.9 \mathrm{~mm}$
\end{tabular}


cracks on slabs incorporating $80 \mathrm{~kg} / \mathrm{m}^{3}$ of fibers, and these slabs did not exhibit crater or concrete spalling at rear face. These results confirm the benefits of increasing the fiber content on flexure crack and spalling control.

For the case of blast Test 3 corresponding to a smaller scaled distance than blast Test 2, all slabs exhibited flexure cracks. While slabs $\mathrm{P}$ and $\mathrm{L}_{30}-40$ were fractured, $\mathrm{L}_{60}-40$ presented wide flexure cracks controlled by the fibers on both faces of the slab. The comparison of these responses suggests that longer fibers are more efficient controlling flexure cracks than shorter fibers.

Slabs incorporating $80 \mathrm{~kg} / \mathrm{m}^{3}$ of fibers presented very thin flexure cracks on the front face and preserved its integrity. The cracks on $\mathrm{L}_{60}-80$ rear face were much thinner than those in $\mathrm{L}_{60}-40$. Moreover, the small crater observed in slab $\mathrm{L}_{60}-40$ did not appear in $\mathrm{L}_{60}-80$. The advantage of fiber addition is again evident in these results. The permanent deflection of slab $\mathrm{L}_{60}-40$ can be clearly identified on the front face where circular cracks produced by the clamping effect of the supports can also be observed.

Table 7 summarizes the maximum cracks widths measured on HSFRC slabs differentiating the front, rear and lateral faces of each blast test. The maximum slabs residual deflection is also included.

\subsection{Numerical results}

First, in order to verify the TNT equivalence of the explosive used in the tests, the propagation of the blast wave resulting from an explosion of $1.54 \mathrm{~kg}$ of explosive elevated $1.0 \mathrm{~m}$ over the ground was numerically simulated. According to the TNT equivalence given by the explosive provider, this amount of explosive corresponds to $1.0 \mathrm{~kg}$ of equivalent TNT. The pressure time history numerically obtained for $1.0 \mathrm{~kg}$ of TNT is compared to the pressure time-history recorded in a sensor located at $15 \mathrm{~m}$ from the explosion in Fig. 2 [37]. The slight differences found between numerical values of peak pressure and duration of the positive phase obtained with the nominal TNT equivalence and experimental values confirm that the TNT equivalence of 0.65 is correct.

Once the TNT equivalence was verified, the tests of $\mathrm{P}$ slabs were reproduced to calibrate the erosion limit of HSC [38]. It is generally recommended to use erosion limits as great as possible. It is noted that for flexure failure, when the erosion limit is increased above certain value, the only difference in the numerical results is the aspect of the deformed structure. But this is not the case of spall damage and cratering.

A good agreement between numerical and experimental final damage patterns was obtained for an erosion limit of 0.1 for P slabs under blast Tests 1 to 3, see Fig. 3. Not only fractures but also spalling damage are approximately reproduced with this erosion limit that is in the range of the values normally used for concrete and is much greater than the minimum strain to failure. Numerical results in blast Test 1 show the damaged slab on the support. Nevertheless, if the numerical simulation is continued some of the slab pieces will probably fall down due to gravitational effects. In contrast, in the case of blast Tests 2 and 3, the numerical results show the slab pieces lying on the ground and the slabs are evidently more damaged in the case of blast Test 3 than in the case of blast Test 2. The diagonal fractures observed in the tests are numerically reproduced.

The numerical results of HSFRC slabs are presented in Figs. 4-7. It is observed that for the blast Tests 2 and 3 the values of tensile strength and minimum strain to failure obtained from the static tests were used and the erosion limit was adjusted as indicated in Table 5 to reproduce the experimental damage patterns. As a rule, the minimum strain to failure controls the appearance of macro cracks and the erosion limit defines total fracture. Due to fibers contribution, both values are greater than those corresponding to HSC. However, while minimum strain to failure increases with fiber content, the erosion limit remains constant. Although the fibers L30 and L60 are different they have similar slenderness, thus the same values of minimum strain to failure were obtained from static tests of HSFRC with the same fiber content and the same value of erosion strain was calibrated for the HSFRC including fibers L30 and L60.

A good agreement between numerical and experimental results was obtained. The numerical simulations showed that slab $\mathrm{L}_{60}-40$ did not fail in blast Test 3 but was near failure. The difference observed with slab $L_{30}-40$ that failed in blast Test 3 was probably due to a slight difference in the effective fiber content or fibers distribution.

In all cases, blast Test 1 (contact explosion) on HSFRC slabs could not be reproduced using RHT model with the parameters presented in Tables 4 and 5. This is because these parameters affect flexure fracture, cratering and spalling and it was already observed that the effectiveness of long fibers to control fracture is greater than the ability to control spalling and cratering. Different trials showed that the results obtained for HSFRC slabs under contact blast loads were better reproduced considering an elastic brittle behavior. The results in Figs. 4-7 for blast Test 1 correspond to an elastic brittle behavior with failure defined by hydrotensile limit (minimum pressure: pmin) affected by the dynamic amplification (DIF) defined by Eq. (9). The corresponding parameters are presented in Table 5. It is observed that while the erosion limit used for $\mathrm{L}_{60}-40$ and $\mathrm{L}_{60}-80$ was the same used for HSC, a greater value was used for $\mathrm{L}_{30}-40$ and $\mathrm{L}_{30}-80$. For these parameters, the dimensions of the crater and spalling areas obtained are presented in Table 6 and most of them are similar to those experimentally observed. Like in the blast tests, a spalling zone not completely separated from the slab rear face is numerically obtained for slabs $\mathrm{L}_{30}-40$ and $\mathrm{L}_{30}-80$. The better performance of the elastic model only including hydrotensile failure suggests that the dynamic amplification (DIF) defined by Eqs. (8) and (9) in RHT concrete model was not enough to represent dynamic strength amplification of HSFRC for very high strain rates like those appearing in these contact blast experiments [39].

\section{Conclusions}

The effect of incorporating different contents of hooked-end high carbon steel fibers of different lengths in a HSC matrix on blast response was experimentally and numerically studied. The following conclusions can be drawn.

The incorporation of fibers, not only increases residual loading capacity and toughness under static loads but also significantly improves blast behavior. Flexural crack thickness, erosion and spalling zones dimensions and permanent deflections are reduced with the increase fiber content.

The addition of hooked end fibers to HSC changes the blast response and the type of damage and failure of the slabs, preserving their integrity. Fibers help to control flexural cracks sewing their lips. However, the effectiveness of fibers controlling the erosion produced by triaxial compression or tension stress states that disintegrate the matrix leading to cratering or matrix spalling is lower.

For the same fiber content, shorter fibers lead to a greater improvement of the matrix behavior and they are more effective controlling cratering and spalling as there are more fibers per unit volume.

The effect of fibers controlling concrete cratering and spalling under contact or close in explosion is not easy to predict using simplified formulas available in the literature. Moreover, it was observed that it is related not only to the fiber content but also to their geometry. In contrast with the observations of other authors, the spalling strength improvement due to fiber addition cannot be directly associated with fracture energy improvements obtained by the addition of fibers.

The response time of the plates was not recorded because it was the first series of tests on these materials and it was expected that most of the slabs fail damaging the accelerometers. Now, that the blast resistance of HSFRC plates has been checked a series of tests including the response time records of the plates can be performed.

The numerical simulations show that homogeneous models are not able to reproduce HSFRC behavior under the whole range of scaled 
distances studied in this paper. It is not easy to calibrate concrete models to accurately reproduce flexure failure, cratering and spalling. The calibration performed for the numerical simulations had the only objective of understanding the effect of fibers on material behavior under blast loads. Available tests are not enough to completely calibrate a dynamic HSFRC model. The accurate modelling of HSFRC under contact blast loads requires further study. Nevertheless, some conclusions can be obtained from the numerical simulation presented.

It was confirmed that near explosions failure is controlled by material properties related to flexure strength and deformation capacity that mainly depend on fiber type and content. For the fibers studied in this paper, erosion value used to represent fracture failure of HSFRC with more than $0.5 \%$ fibers content can be taken as 10 times that of the matrix and it is the same for the same fibers slenderness.

For contact explosions, due to the very high loading rates, HSFRC behaves like an elastic brittle material with improved strength but erosion limit should be less than that used for flexure failure. When the matrix is eroded, the fibers are loose and cannot longer contribute to the composite strength. If the fibers are too long like fibers $\mathrm{L}_{60}$ they cannot prevent matrix erosion so the same erosion limit of the matrix should be used. Shorter fibers are better at improving the matrix and in correspondence, the erosion limit for HSFRC including shorter fibers is greater than that of the matrix but lower than that used for flexure failure. As in the case of fracture failure, erosion limit can be taken constant for fibers contents greater than $0.5 \%$ in volume.

It should be emphasized that erosion algorithms and limits calibrated with damage patterns for the particular HSC and HSFRC presented in this paper should be taken as an orientation. One cannot yet rely on predictions of dynamic behavior using these algorithms and erosion values. More research should be done in this area.

\section{Acknowledgement}

The cooperation in the blast tests of Prof. Oscar Curadelli, Bioeng. Gabriel Houri, Dr. Eng. Martín Domizio and Dr. Eng Hernán Garrido are specially acknowledged. The authors wish to thank the financial support of National Agency for Scientific and Technological Promotion (PICT 2013 1740), National Scientific and Technological Research Council (CONICET), LEMIT-CIC, National University of Tucumán Research Council (PIUNT 2013 26E520), National University of Cuyo and Ms. Amelia Campos for the English revision. The companies Cementos Avellaneda S.A., Ferrocement S.A, N.V. Bekaert S.A. and Sika Argentina S.A.I.C. that provided the cement, the silica fume, the steel fibers and the chemical admixtures and ESSS Argentina (ANSYS) are also greatly acknowledged.

\section{References}

[1] Kustermann A, Thienel K, Bludau C, Keuser M, Zimbelmann R. Protection elements made of high strength fiber reinforced concrete (HSFRC) as single and multi layer constructions. In: Proceedings of the $12^{\text {th }}$ International symposium on interaction of the effects of munitions with structures. New Orleans, USA; 2005.

[2] Millard SG, Molyneaux TCK, Barnett SJ, Gao X. Dynamic enhancement of blastresistant ultra high performance fibre-reinforced concrete under flexural and shear loading. Int J Impact Eng 2010;37:405-13.

[3] Wang S, Zhang M-H, Quek ST. Mechanical behavior of fiber-reinforced highstrength concrete subjected to high strain-rate compressive loading. Constr Build Mater 2012;31:1-11.

[4] Tran NT, Tran TK, Kim DJ. High rate response of ultra-high-performance fiber-reinforced concretes under direct tension. Cem Concr Res 2015;69:72-87.

[5] Caverzan A, Cadoni E, di Prisco M. Tensile behaviour of high performance fibrereinforced cementitious composites at high strain rates. Int J Impact Eng 2012;45:28-38.

[6] Zhou XQ, Kuznetsov VA, Hao H, Waschl J. Numerical prediction of concrete slab response to blast loading. Int J Impact Eng 2008;35:1186-200.

[7] Ngo T, Mendis P, Krauthammer T. Behavior of ultrahigh-strength prestressed concrete panels subjected to blast loading. J Struct Eng 2007;133(11):1582-90.
[8] Yi N-H, Kim J-H, Han T-S, Cho Y-G, Lee JH. Blast-resistant characteristics of ultrahigh strength concrete and reactive powder concrete. Constr Build Mater 2012;28(1):694-707.

[9] Aoude H, Dagenais FP, Burrell RP, Saatcioglu M. Behavior of ultra-high performance fiber reinforced concrete columns under blast loading. Int J Impact Eng 2015;80:185-202.

[10] Ellis BD, Di Paolo BP, McDowell DL, Zhou M. Experimental investigation and multiscale modeling of ultra-high performance concrete panels subject to blast loading. Int J Impact Eng 2014;69:95-103.

[11] Mao L, Barnett SJ, Tyas A, Warren J, Schleyer GK, Zaini SS. Response of small scale ultra high performance fibre reinforced concrete slabs to blast loading. Constr Build Mater 2015;93(15):822-30.

[12] Thoma K, Stolz A, Millon O. Performance and suitability of ultra-high-performance concrete under a broad range of dynamic loadings. In: Hao H, Li Z-X, editors. Advances in protective structures research. IAPS Special publication 1. Chapter 3. London: London Taylor \& Francis; 2012. p. 65-96.

[13] Li J, Wu Ch, Hao H, Wang Z, Su Y. Experimental investigation of ultra-high performance concrete slabs under contact explosions. Int J Impact Eng 2016;93:62-75.

[14] Nam J, Kim H, Kim G. Experimental investigation on the blast resistance of fiberreinforced cementitious composite panels subjected to contact explosions. Int J Concr Struct Mater 2017;11(1):29-43.

[15] Wu C, Oehlers DJ, Rebentrost M, Leach J, Whittaker AS. Blast testing of ultra-high performance fibre and FRP-retrofitted concrete slabs. Eng Struct 2009;31:2060-9.

[16] Li J, Hao H. Numerical study of concrete spall damage to blast loads. Int J Impact Eng 2014;68:41-55.

[17] Hung CC, Li SH. Three-dimensional model for analysis of high performance fiber reinforced cement-based composites. Compos B 2014;45:1441-7.

[18] Liu H, Xiang T, Zhao R. Research on non-linear structural behaviors of prestressed concrete beams made of high strength and steel fiber reinforced concretes. Constr Build Mater 2009;23:85-95.

[19] Tysmans T, Wozniak M, Remy O, Vantomme J. Finite element modelling of the biaxial behavior of high-performance fibre-reinforced cement composites (HPFRCC) using Concrete Damaged Plasticity. Finite Elem Anal Des 2015;100:47-53.

[20] Gal E, Kryvoruk R. Meso-scale analysis of FRC using a two-step homogenization approach. Comput Struct 2011;89:921-9.

[21] Ren X, Li J. Multi-scale based fracture and damage analysis of steel fiber reinforced concrete. Eng Fail Anal 2013;35:253-61.

[22] Mao L, Barnett S, Begg D, Schleyer G, Wight G. Numerical simulation of ultra high performance fibre reinforced concrete panel subjected to blast loading. Int J Impact Eng 2014;64:91-100.

[23] Fang Q, Zhang J. Three-dimensional modelling of steel fiber reinforced concrete material under intense dynamic loading. Constr Build Mater 2013;44:118-32.

[24] Li J, Zhang Y. Evaluation of constitutive models of hybrid-fibre engineered cementitious composites under dynamic loadings. Constr Build Mater 2012;30:149-60.

[25] Luccioni B, Isla F, Codina R, Ambrosini D, Zerbino R, Giaccio G, et al. Effect of Steel fibers on static and blast response of high strength concrete. Int J Impact Eng 2017; 107:23-37.

[26] EN 14651:2005, Test method for metallic fibered concrete - Measuring the flexural tensile strength (limit of proportionality (LOP), residual). CEN-European Committee for Standardization, Brussels June 2005:1-17.

[27] Fédération Internationale du Béton. fib Model Code for concrete structures 2010 Lausanne: Ernst \& Sohn; 2013.

[28] ANSYS, AUTODYN Version 18.1 User's Manual, 2017.

[29] Luccioni B, Ambrosini R, Danesi R. Analysis of building collapse under blast loads. Eng Struct 2004;26:63-71.

[30] Riedel W, Kawai N, Kondo K. Numerical assessment for impact strength measurements in concrete materials. Int J Impact Eng 2009;36:283-93.

[31] Herrmann W. Constitutive equation for the dynamic compaction of ductile porous materials. J Appl Phys 1969;40(6):2490-9.

[32] Tu Z, Lu Y. Evaluation of typical concrete material models used in hydrocodes for high dynamic response simulations. Int J Impact Eng 2009;36:132-46.

[33] Luccioni B, Isla F. Simulación de hormigones de alta resistencia reforzados con fibras bajo cargas cuasiestáticas. Mecánica Computacional 2016;35:2583-98.

[34] Tu Z, Lu Y. Modifications of RHT material model for improved numerical simulation of dynamic response of concrete. Int J Impact Eng 2010;37:1072-82.

[35] Tai Y-H, El-Tawil S, Chung T-H. Performance of deformed steel fibers embedded in ultra-high performance concrete subjected to various pullout rates. Cem Concr Res 2016;89:1-13.

[36] Pyo S, El-Tawil S, Naaman AE. Direct tensile behavior of ultra high performance fiber reinforced concrete (UHP-FRC) at high strain rates. Cem Concr Res 2016;88:144-56.

[37] Codina R, Ambrosini D, de Borbón F. Alternatives to prevent the failure of RC members under close-in blast loadings. Eng Fail Anal 2016;60:96-106.

[38] Luccioni B, Araoz G, Labanda N. Defining erosion limit for concrete. Int J Protective Struct 2013;4(3):315-40.

[39] Kong X, Fang K, Li QM, Wu H, Crawford JE. Modified K\&C model for cratering and scabbing of concrete slabs under projectile impact. Int J Impact Eng 2017;108:217-28. 